\title{
BACTERIAL DISCRIMINATION OF DRINKING WATER THROUGH OF AN ELECTRONIC NOSE AND A VOLATILES EXTRACTION EQUIPMENT
}

\section{DISCRIMINACIÓN DE BACTERIAS EN AGUA POTABLE A TRAVÉS DE UNA NARIZ ELECTRÓNICA Y UN EQUIPO DE EXTRACCIÓN DE VOLÁTILES}

\author{
MSc. Jeniffer Katerine Carrillo Gómez*, PhD. Cristhian Manuel Duran Acevedo**, \\ PhD. Ramon Ovídio Garcia Rico*** \\ "Universidad de Pamplona, Facultad de ciências básicas, Grupo de investigación GISM. \\ E-mail: jeniffer.carrillo@unipamplona.edu.co \\ *** Universidad de Pamplona, Facultad de ingenierías y arquitectura, Grupo de investigación \\ GISM \\ E-mail: cmduran@unipamplona edu.co \\ ***Universidad de Pamplona, Facultad de Ciencias Básicas, Grupo de investigación \\ GIMBIO. \\ E-mail: ovidio.garcia@unipamplona.edu.co
}

\begin{abstract}
Resumen: Este consiste de un sistema de extracción de volátiles y una nariz electrónica para detectar especies bacterianas emitidas en muestras de agua contaminada, este muestreador es acoplado a un sistema de percepción sensorial compuesto por una cámara de 16 sensores de óxidos metálicos usada como una alternativa de monitoreo continuo para la detección e identificación de las bacterias, con tiempos de respuesta rápido, bajo costo, en comparación con los métodos convencionales. Para probar el método se realizaron diferentes medidas de agua estéril y agua contaminada con Escherichia coli a temperaturas de 50,70 y $90^{\circ} \mathrm{C}$, con el fin de obtener un patrón característico de cada compuesto, adicionalmente se evaluó el potencial para la detección de diferentes especies bacterianas (Escherichia coli, Klebsiella oxytoca y Pseudomonas aeruginosa) y agua de grifo estéril. Los resultados demostraron que es posible discriminar muestras de agua contaminada de agua estéril. Para el procesamiento de los datos fueron usados diferentes técnicas de reconocimiento de patrones, tales como el PCA, DFA y la red neuronal PNN, donde un $95 \%$ de discriminación fue obtenido usando PCA, 100\% de éxito en la clasificación con el método de validación cruzada "leave one out" y $92 \%$ con el clasificador DFA.
\end{abstract}

Palabras clave: COV's, espacio de cabeza, microorganismos, sensores de gases, procesamiento, Calidad del agua.

\begin{abstract}
This study consists of a volatiles extraction system and an electronic nose to detect bacterial species emitted from contaminated water samples, this sampler was coupled to a sensory perception system composed of a chamber of 16 metal oxide gas sensors used as an alternative of continuous monitoring for bacterial detection and identification, with fast response times, low cost compared with conventional methods. To test the method, different measurements of sterile water and contaminated water with "Escherichia coli" were made at temperatures of $50^{\circ} \mathrm{C}, 70^{\circ} \mathrm{C}$ and $90^{\circ} \mathrm{C}$ in order to obtain a characteristic pattern of each compound; additionally to determine the potential for the detection of different bacterial species (Escherichia coli, Klebsiella oxytoca and Pseudomonas aeruginosa) and sterile tap water. The results obtained showed that it is possible to discriminate samples of contaminated water from sterile water. For the data processing, different pattern recognition techniques were used, such as the PCA, DFA and
\end{abstract}


the PNN neural network, where $95 \%$ discrimination was obtained using PCA, $100 \%$ of success rate of classification with a cross-validation method and $92 \%$ with the DFA classifier.

Keywords: VOC's, headspace, Microorganism, Gas sensor, Processing, Water Quality.

\section{INTRODUCCIÓN}

La Organización Mundial de la Salud (OMS) en las guías para la calidad del agua potable, establece la ausencia de cualquier microorganismo en el agua potable para consumo humano que pueda afectar la salud del consumidor, este parámetro es utilizado como guía de calidad para la creación de reglamentos o normas, también sirve para evaluar los riesgos de contaminación, vigilar los procesos de tratamiento y hacer planes correctivos para alcanzar la calidad deseada. En Colombia la calidad microbiológica solo incluye el control de bacterias como coliformes totales y fecales. Para la detección de los contaminantes microbiológicos en agua se usan técnicas convencionales como: Fermentación de tubos múltiples, filtración por membrana, enzima sustrato, sustrato definido, entre otros, sin embargo, hay que recalcar que estos métodos son tediosos, representan altos costos, tiempos de análisis, siendo un obstáculo para establecer la calidad microbiana del agua para consumo humano. La Fig. 1a muestra un esquema general de las etapas y el tiempo requerido para detectar e identificar los contaminantes por medio de los métodos convencionales.

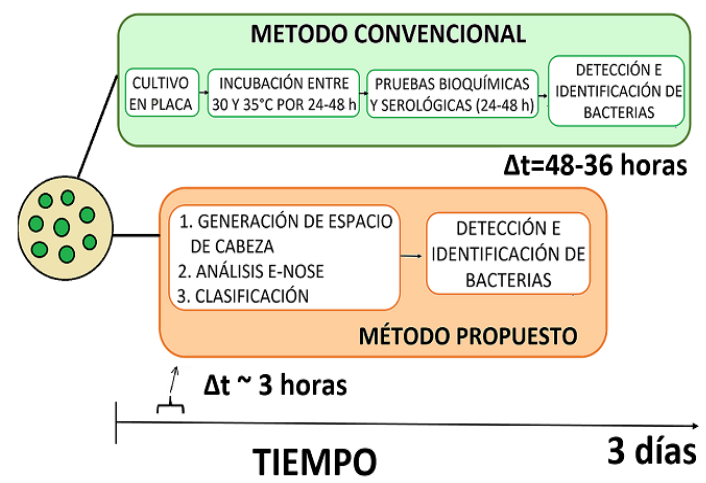

Fig. 1. Vista simplificada de detección e identificación de bacterias a). Métodos convencionales y b). Método propuesto.

Una forma de evaluar la calidad microbiológica del agua para el consumo humano, es monitorear constantemente un indicador bacteriano tan importante como Escherichia coli (Edberg et al., 2012) una bacteria Gram (-) de la familia Enterobacteriaceae, considerada el principal integrante del grupo de los coliformes fecales. Actualmente existe una gran limitación para determinar E. coli u otro tipo de bacterias en el agua, esto se debe a que la mayoría de plantas de tratamiento de agua potable no cuentan con laboratorios, tecnologías especializadas, equipos, insumos, personal capacitado que permita realizar dichas pruebas microbiológicas, limitando su frecuencia de análisis ( 1 a 2 veces al mes), ya que deben enviarse muestras a laboratorios certificados generando costos, errores derivados del muestreo que pueden alterar los análisis y retrasos en la obtención de resultados, es por eso que las limitaciones de los métodos convencionales han llevado a que las investigaciones se centren en el desarrollo de métodos rápidos y precisos para identificar bacterias.

Para un monitoreo continuo, tiempos de respuesta rápido y bajo costo (ver Fig. 1b), se han desarrollado nuevas técnicas usando un sistema multisensorial (olfato electrónico), este se ha investigado como una alternativa, reemplazando los métodos convencionales usados para la detección e identificación de bacterias. (Gardner et al., 1998; McEntegart et al., 2000; Lakshmanan et al., 2007; Siripatrawan's, 2008; Green et al., 2011; Krishnamurthy et al., 2012; Nuñez et al., 2013; Geoffrey et al., 2014).

Según las investigaciones el sistema de olfato electrónico se puede utilizar para el análisis específico, identificación y reconocimiento de olores complejos y compuestos orgánicos volátiles, ya que está conformado por un conjunto de sensores de gases químicos con sensibilidades parcialmente solapadas. (Duran, 2005). Dentro de los subsistemas del equipo multisensorial se encuentra la etapa de acondicionamiento de la muestra, por lo tanto, es importante preparar la muestra con las condiciones adecuadas con el objetivo de que los sensores de gases tengan buena sensibilidad y selectividad a la hora de detectar los COV's emanados por las especies bacterianas. Una forma de aumentar la sensibilidad y selectividad es incorporando métodos de concentración de la muestra, para ello existen técnicas como la microextracción en fase solida (SPME) que consta de dos pasos: extracción y desorción del analito, aunque este método es muy eficaz depende de ciertos parámetros de muestreo como el tipo de 
recubrimiento de la fibra (los COV's varían de acuerdo al tipo de fibra), el tiempo de extracción, tiempo de equilibrio, la temperatura de extracción y desorción. Adicionalmente existen técnicas de extracción de volátiles como el de espacio de cabeza (HS) dinámico y estático, la primera consiste en someter una muestra a una temperatura determinada mediante un gas inerte. (Herrero et al., 2016). Los compuestos volátiles son retenidos posteriormente en una trampa adsorbente, que a continuación se somete a desorción mediante un disolvente y se inyecta para su separación por cromatografía de gases. La técnica de espacio de cabeza estático es de aplicación muy simple y bajo costo, es por eso que en esta investigación se diseñó e implementó un equipo de extracción de volátiles, el cual consiste en introducir la muestra en un vial cerrado mediante un septum, aplicando una determinada temperatura con el objeto de extraer una alícuota de la fracción de vapor con una jeringa para muestras gaseosas, que se inyectan en el cromatógrafo de gases y espectrómetro de masas (GC-MS) (Sauer et al., 2010), en nuestro caso a un sistema de olfato electrónico compuesto por 16 sensores de óxido metálico, que transforman las señales recibidas en señales eléctricas, adquiriendo la información y extrayendo rasgos característicos de las muestras examinadas. A través de métodos de reconocimiento de patrones tales como: Análisis de Componentes Principales (PCA), función de discriminantes (DFA), redes neuronales (PNN) o inteligencia artificial, se discriminaron y/o clasificaron los compuestos generados por las diferentes muestras.

\section{METODOLOGÍA}

La Fig. 2, describe cada uno de los pasos que se llevaron a cabo para el desarrollo de la metodología propuesta. En ella se puede apreciar como primer paso la preparación y adecuación de las muestras en los viales, seguido de un equipo de extracción de volátiles, acoplado a un sistema de percepción sensorial. Para la adquisición, control y monitoreo de las señales originadas por los sensores se usó una tarjeta de adquisición de datos conectada a la cámara de sensores y el PC.

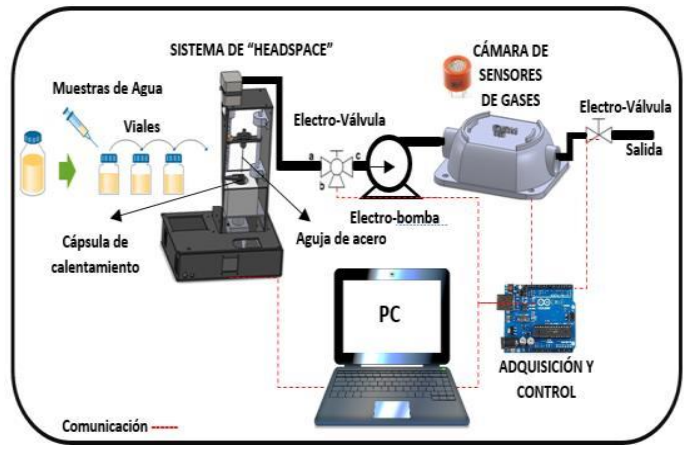

Fig. 2. Esquema general de la metodología implementada.

En resumen, la metodología propuesta consta de 5 etapas, las cuales se describen a continuación.

\subsection{Diseño del equipo de extracción de volátiles.}

En la Fig. 3 se ilustra cómo está compuesto equipo de extracción de volátiles.

1) Motor paso a paso para el control de tornillo sin fin del inyector.

2) Inyector

3) Celda calefactora

4) Fuente de alimentación (5-12VDC)

5) Interfaz táctil LCD

6) Carcasa base

7) Conector de alimentación alterna

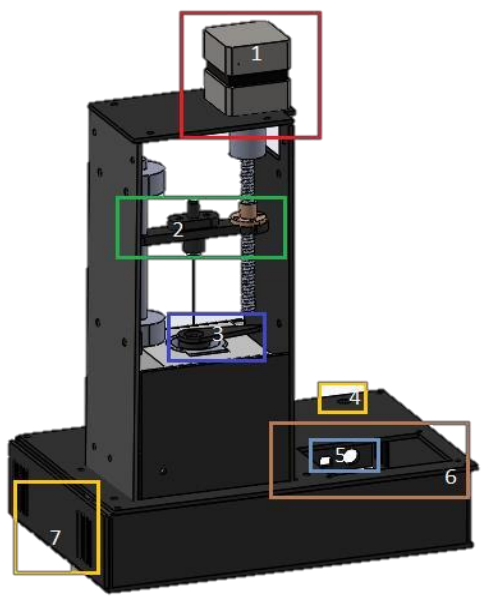

Fig. 3. Diseño del equipo de extracción de volátiles. .

El funcionamiento del sistema está basado en el control de temperatura de la celda calefactora y el accionamiento de un motor paso a paso para el control del inyector.

El proceso comienza en el momento de ubicar un vial de $20 \mathrm{ml}$ dentro de la celda calefactora, esta es 
accionada automáticamente, la cual es alimentada con un voltaje de 120 VAC y sucesivamente es controlada por una salida analógica con Modulación Ancho de Pulso (PWM), configurada en una tarjeta Arduino Mega, la cual es regulada mediante un controlador PID embebido. La temperatura referenciada es censada a través de un termopar Tipo $\mathrm{K}$ y es mantenida por dicho controlador. Una vez el vial alcance la temperatura deseada, automáticamente el motor paso a paso es accionado con el objetivo de desplazar el inyector hacia el septum del vial mediante un tornillo sin fin, y extraer los compuestos generados por el calentamiento. Dicha extracción es llevada a cabo por una electrobomba, la cual se accionada automáticamente por una salida digital de 5 VDC del Arduino que acciona a la bobina de un relé para el control de la bomba.

\subsection{Sistema de olfato electrónico}

En este estudio se implementó una nariz electrónica llamada B-NOSE, desarrollada en la universidad de Pamplona (Rodríguez et al., 2008). En la Tabla 1 se describen los 16 sensores gases de óxidos metálicos, Taguchis de la empresa FÍGARO sensor.

Tabla 1: Matriz de sensores Bnose.

\begin{tabular}{cll}
\hline Sensor & \multicolumn{1}{c}{ Aplicación } & \multicolumn{2}{c}{ Detección } \\
\hline TGS 800R & $\begin{array}{l}\text { Control de } \\
\text { calidad del aire }\end{array}$ & $\begin{array}{l}\text { Aire contaminado: } \\
\text { Tabaco, gasolina, } \\
\text { etc. }\end{array}$
\end{tabular}

\begin{tabular}{llllr}
\hline TGS 822 & $\begin{array}{l}\text { Detección } \\
\text { vapores } \\
\text { alcohol }\end{array}$ & $\begin{array}{l}\text { de } \\
\text { de }\end{array}$ & $\begin{array}{l}\text { Alcohol, Tolueno, } \\
\text { Xileno, etc. }\end{array}$ \\
\hline TGS 825 & $\begin{array}{l}\text { Detección de gas } \\
\text { tóxico }\end{array}$ & $\begin{array}{l}\text { Sulfuro } \\
\text { hidrogeno }\end{array}$ & de \\
\hline TGS 826 & $\begin{array}{l}\text { Detección de gas } \\
\text { tóxico }\end{array}$ & Amoníaco & \\
\hline TGS 880 & $\begin{array}{l}\text { Control } \\
\text { cocinas }\end{array}$ & de & $\begin{array}{l}\text { Gases volátiles, } \\
\text { vapor de agua en } \\
\text { alimentos }\end{array}$ \\
\hline
\end{tabular}

\begin{tabular}{llll}
\hline TGS 882 & $\begin{array}{l}\text { Control } \\
\text { cocinas }\end{array}$ & de & $\begin{array}{l}\text { Vapor de alcohol } \\
\text { en los alimentos }\end{array}$ \\
\hline TGS 813 & $\begin{array}{l}\text { Detección de gas } \\
\text { combustible }\end{array}$ & $\begin{array}{l}\text { Hidrocarburos en } \\
\text { general }\end{array}$ & \\
\hline
\end{tabular}

TGS 821 $\begin{aligned} & \text { Detección de gas hidrogeno } \\ & \text { combustible }\end{aligned}$

TGS 831, Detección de gas R-22

\begin{tabular}{lll}
\hline TGS 830 & Halocarbon & \\
\cline { 1 - 2 } TGS 842 & $\begin{array}{l}\text { Detección de gas } \\
\text { combustible }\end{array}$ & Gas natural metano \\
\cline { 2 - 3 } TGS 832 & $\begin{array}{l}\text { Detección de gas } \\
\text { combustible }\end{array}$ \\
\hline
\end{tabular}

La nariz fue acoplada al sistema de extracción de volátiles mediante un tubo de acero inoxidable de $1 / 2$ pulgada con el fin de llevar la muestra hacia la cámara de sensores, sin pérdida importante de los COV's generados desde el contenedor de la muestra (vial). Con esta configuración fue posible obtener un conjunto de medidas repetitivas con diferentes rangos de temperatura y ciclos de adquisición de la muestra.

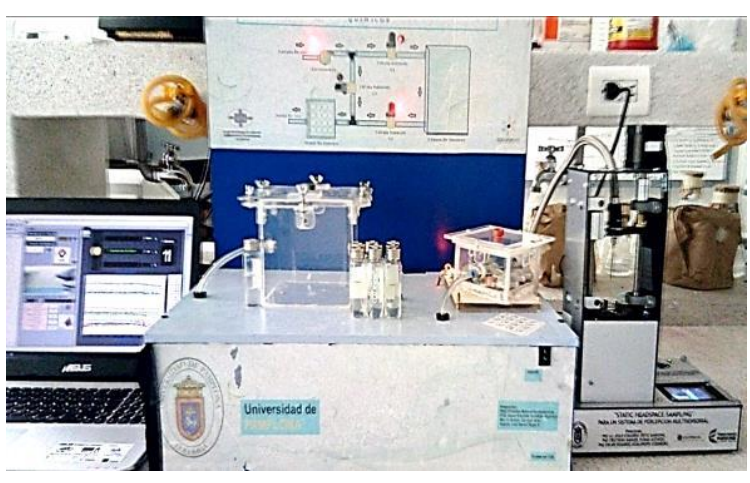

Fig. 4. Nariz electrónica B-NOSE acoplado al sistema de extracción de volátiles.

\subsection{Acondicionamiento de las muestras}

Para esta investigación se trabajó con tres tipos de muestras, que se llamaron controles. El control negativo consistió en agua estéril (llevada a una autoclave por un tiempo de 15 minutos a una temperatura de $121,1{ }^{\circ} \mathrm{C}$ ), el control positivo se preparó usando agua estéril que fue inoculada con Escherichia coli (cepa ATCC 25922), y por último los controles de especificidad se prepararon con muestras de agua estéril contaminadas de manera controlada con las bacterias Pseudomonas aeruginosa (ATCC 27853) y Klebsiella oxytoca (ATCC 49131). 


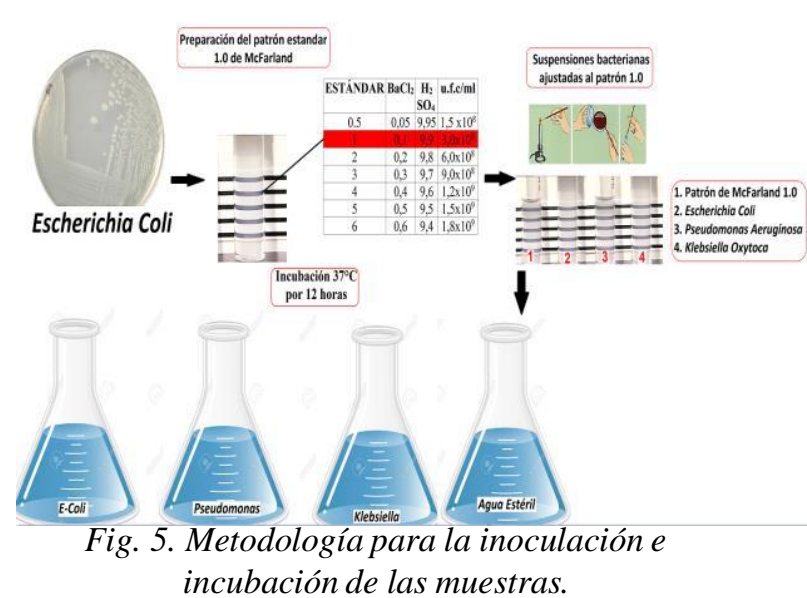

La Fig. 5 muestra el procedimiento básico llevado a cabo para la preparación de los controles. Para la preparación de los controles, positivo y de especificidad, se partió de una placa de Petri con una siembra por agotamiento de cada una de las bacterias en un medio de cultivo solido llamado agar nutritivo.

A partir de estas siembras se preparó una suspensión bacteriana a una concentración de $3 \times 10^{8}$ bacterias/mililitro, usando como referencia para ello el patrón $\mathrm{N}^{\circ} 1.0$ de la escala de McFarland. Estos estándares son usados como una relación entre una precipitación química y una suspensión bacteriana, ajustando la turbidez de suspensiones bacterianas hasta que el número de bacterias llegue a la concentración deseada (Zapata et al., 2015) (J Guzmán-Luna, ID Torres, 2017). Posteriormente, esta suspensión bacteriana fue diluida 30 veces en agua estéril para obtener 300 $\mathrm{ml}$ tanto del control positivo como de los controles de especificidad, con una concentración final de $1 \times 10^{7}$ bacterias $/ \mathrm{ml}$. Finalizada la dilución, las muestras fueron incubadas durante 12 horas a $37^{\circ} \mathrm{C}$ con el objetivo de mejorar el enriquecimiento de los compuestos generados.

\subsection{Realización de las medidas}

La toma de medidas, se dividió en dos etapas.

\subsubsection{Primera etapa.}

La primera etapa consistió en analizar muestras de agua estéril y Escherichia coli, modificando la temperatura de incubación en los viales $\left(50^{\circ} \mathrm{C}\right.$, $70^{\circ} \mathrm{C}$ y $90^{\circ} \mathrm{C}$ ), esto se hizo con el objetivo de verificar la temperatura optima a la cual el olfato electrónico acoplado al equipo de extracción consigue discriminar entre el control negativo y la muestra con el analito (E. coli).

En la Tabla 2, se encuentran los parámetros usados para analizar las muestras de agua y E. Coli.

\section{Tabla 2. Parámetros usados para la discriminación de las muestras.}

\begin{tabular}{lcc}
\hline \multicolumn{3}{c}{ Parámetros del equipo de extracción de } \\
volátiles
\end{tabular}

\subsubsection{Segunda etapa}

Una vez finalizada la etapa 1 y de acuerdo con los resultados obtenidos, se escogió la temperatura óptima de mejor clasificación del agua estéril y $E$. coli $\left(50^{\circ} \mathrm{C}\right)$ para realizar pruebas de especificidad/selectividad del método propuesto. En la especificidad del métodos propuesto para diferenciar el analito de interés, en este caso $E$. coli, que es una bacteria indicadora de contaminación fecal en aguas (control positivo), de otros analitos que son similares y pueden tender a la confusión. Por esta razón para ello se escogieron como controles de especificidad a Pseudomonas aeruginosa, una bacteria Gram (-) de importancia en aguas y Klebsiella oxytoca otra bacteria Gram (), perteneciente a la misma familia de $E$. coli, la Enterobacteriaceae, y que es clasificada dentro del grupo de los coliformes totales, a diferencia de $E$. coli que conforma el de los coliformes fecales. Los resultados obtenidos fueron comparados con la muestra sin contaminación bacteriana, agua estéril (control negativo). Luego de obtener los resultados se evaluó la capacidad del método para producir resultados exactos clasificando las tres especies bacterianas y el agua estéril.

Para realizar el análisis de las muestras se usaron los mismos parámetros detallados en la Tabla 2, con la salvedad de que se usó una única temperatura: $50^{\circ} \mathrm{C}$. 


\subsection{Adquisición de medidas, análisis y procesado de datos.}

La matriz de sensores que hacen parte de la cámara de medición, transforma las reacciones químicas en señales eléctricas. Las señales adquiridas son tratadas por métodos de pre-procesado de datos, en los cuales se puede distinguir dos etapas: Extracción de parámetros, normalización de datos.

(Moreno et al., 2009)

\subsubsection{Extracción de parámetros}

Esta etapa se refiere a la aplicación de una serie de posibles operaciones a la señal proveniente de los sensores para extraer diversos parámetros, tales como: valores de conductancia inicial, máxima, final y sus normalizaciones. Los cuales corresponden a parámetros del tipo estáticos. En este trabajo se ha considerado usar el parámetro de máximo incremento de la conductancia (GmaxGmin) para extraer lo parámetros de cada sensor, donde Gmax es el valor de la respuesta máxima del sensor ante la reacción con el compuesto y Gmin es el valor de línea base y/o el valor del estado estacionario del sensor.

\subsubsection{Normalización de datos.}

Una vez que se han extraído los parámetros de los sensores, es necesario escalarlos para que puedan ser utilizados por los algoritmos de reconocimiento de patrones. Existen diversos tipos de escalado: lineales, logarítmicos, de variables o de medidas. Cabe resaltar que para esta investigación se probaron 4 tipos de normalizado: Auto Escalado, Centrado, por columna y por matriz.

Los datos obtenidos de la etapa anterior, son finalmente analizados por técnicas de reconocimiento de patrones e inteligencia artificial para la toma decisiones, clasificación e identificación de las muestras.

En la Tabla 3 se observa un esquema de las técnicas de reconocimiento de patrones aplicadas a los datos. (Rubio et al., 2016).

Tabla 3. Técnicas de Análisis de Patrones Multivariables aplicadas a los datos de la nariz electrónica

\begin{tabular}{ll}
\hline Técnica & \multicolumn{2}{c}{ Descripción } \\
\hline PCA & Es un método de \\
& proyección \\
& no paramétrico \\
& comúnmente utilizado \\
& para implementar un \\
\hline
\end{tabular}

clasificador supervisado lineal, Es un clasificador paramétrico

DFA supervisado, que puede utilizarse para el análisis tanto cuantitativo como cualitativo

\begin{tabular}{ll}
\hline RED NEURONAL & Es una RNA semi - \\
PROBABILISTICA & supervisada basada en \\
PNN & las redes de decisión \\
& bayesia.na. Es muy \\
& utilizada en problemas \\
& de clasificación. \\
\hline
\end{tabular}

\section{RESULTADOS}

A continuación, se describen los resultados obtenidos a partir de las pruebas realizadas. Primero consideramos el caso del análisis de los datos obtenidos de las muestras de Agua estéril y agua contaminada con Escherichia coli a diferentes temperaturas con el objeto de mejorar el enriquecimiento y buscar la temperatura óptima para promover la volatilización de los COV's y así para aumentar la sensibilidad de los sensores. Se realizaron 10 ensayos por cada tipo de muestra.

En la Fig. 6 y Figura 7, se observa una buena discriminación de los clusters de Agua estéril y Ecoli a $90^{\circ} \mathrm{C}$ usando PCA (96.1\% de varianza) y con mayor acierto en la clasificación usando la técnica DFA (100\% de acierto).

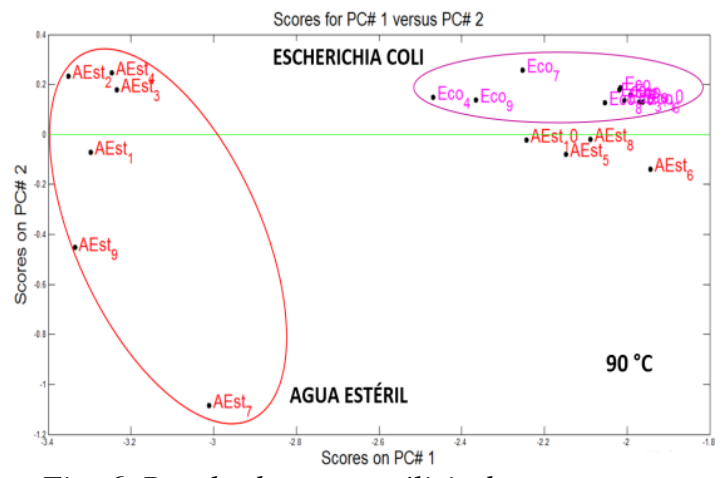

Fig. 6. Resultados con análisis de componentes principales (PCA) de Agua estéril y Escherichia coli $90^{\circ} \mathrm{C}$ 


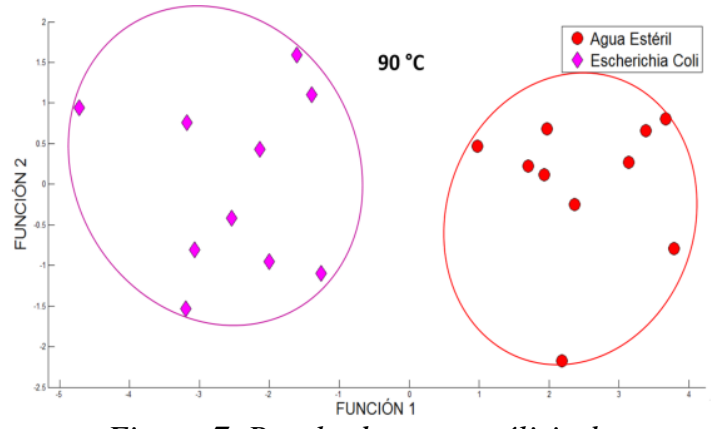

Figura 7. Resultados con análisis de funcionamiento de discriminantes (DFA) de Agua estéril y Escherichia coli a $90^{\circ} \mathrm{C}$

La Fig. 8 ;Error! No se encuentra el origen de la referencia., corresponde a los resultados obtenidos usando PCA (97.8\% de varianza), en ella se observa una buena discriminación entre las muestras contaminadas con E. coli y el control negativo, sin embargo existe una superposición de dos ensayos de agua estéril en el clusters de las muestras de E. coli. La Fig. 9; Error! No se encuentra el origen de la referencia. muestra la diferenciación de clusters por DFA con un $100 \%$ de acierto.

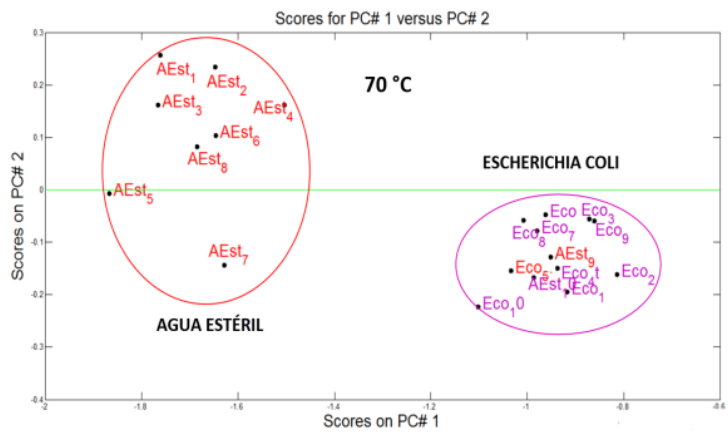

Fig. 8. Resultados con análisis de componentes principales (PCA) de Agua estéril y Escherichia coli a $70^{\circ} \mathrm{C}$

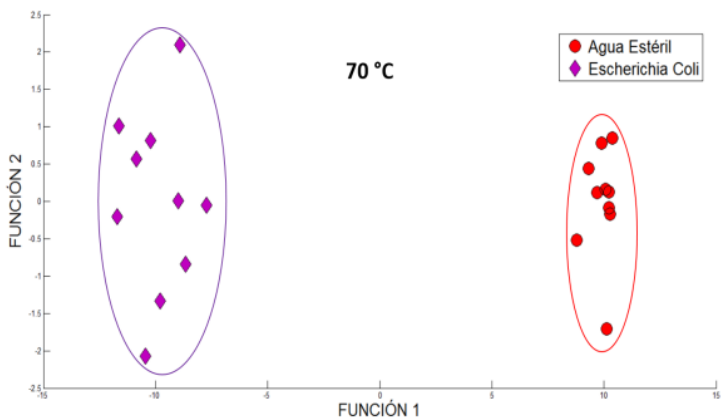

Fig. 9. Resultados con análisis de funcionamiento de discriminantes (DFA) de Agua estéril y Escherichia coli a $70^{\circ} \mathrm{C}$
En los resultados obtenidos en la ;Error! No se encuentra el origen de la referencia. Fig. 10, con el método PCA se puede observar claramente la diferencia entre los dos grupos de medidas con un porcentaje de varianza del $98.7 \%$. Usando el método de DFA se discriminan claramente los clusters de E. coli y agua estéril, con una varianza del 100\%. Fig. 11

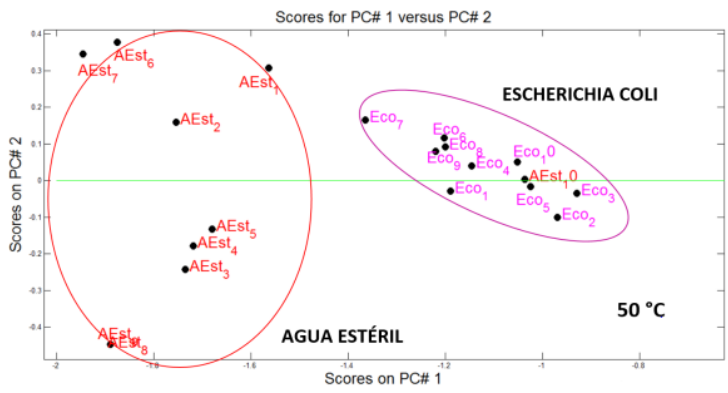

Fig. 10. Resultados con análisis de componentes principales (PCA) de Agua estéril y Escherichia coli a $50^{\circ} \mathrm{C}$

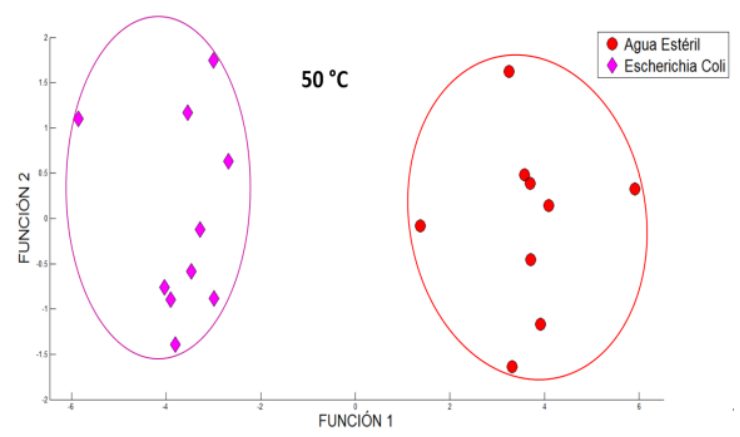

Fig. 11. Resultados con análisis de funcionamiento de discriminantes (DFA) de Agua estéril y Escherichia coli a $50^{\circ} \mathrm{C}$

En la Tabla 4, se muestra un resumen de los métodos de procesado y normalizado usados para el procesado de datos de las diferentes muestras. Anteriormente se mencionó que se evaluó el porcentaje de clasificación mediante las técnicas de PCA y DFA, sin embargo, para obtener una mayor confiabilidad de los datos, se trabajó con una red neuronal probabilística generando un porcentaje de acierto del $100 \%$, adicionalmente para evaluar el desempeño de la red neuronal, en términos de precisión, eficiencia y fiabilidad se utilizó el método interactivo de validación cruzada leave one out que consiste en generar los modelos computando todas las muestra s menos la que se utiliza para validar. Se obtuvo un $90 \%$ de desempeño. 
Tabla 4. Resumen de los métodos de procesado y normalizado usados en las muestras a una temperatura de $50^{\circ} \mathrm{C}$

\begin{tabular}{|c|c|c|c|c|}
\hline \multicolumn{5}{|c|}{ Temperatura : $50^{\circ} \mathrm{C}$} \\
\hline \multirow{2}{*}{$\begin{array}{c}\text { Método } \\
\text { procesad } \\
\text { o }\end{array}$} & \multicolumn{4}{|c|}{ Método normalizado } \\
\hline & $\begin{array}{c}\text { centrad } \\
\text { o } \\
(\%)\end{array}$ & $\begin{array}{c}\text { Auto- } \\
\text { Escalad } \\
0 \\
(\%) \\
\end{array}$ & $\begin{array}{c}\text { Por } \\
\text { column } \\
\text { a } \\
(\%) \\
\end{array}$ & $\begin{array}{l}\text { Por } \\
\text { matri } \\
\mathrm{z} \\
(\%) \\
\end{array}$ \\
\hline PCA & 80.8 & 76.3 & 97.5 & 98.7 \\
\hline DFA & 100 & 100 & 100 & 100 \\
\hline $\begin{array}{c}\text { Red } \\
\text { neuronal } \\
\text { PNN } \\
\end{array}$ & 90 & 100 & 100 & 100 \\
\hline $\begin{array}{c}\text { Red } \\
\text { neurona } \\
\text { PNN con } \\
\text { Leave } \\
\text { one out }\end{array}$ & 0 & 80 & 80 & 90 \\
\hline
\end{tabular}

El efecto de la temperatura de la muestra juega un papel importante en la repetibilidad de los resultados de medición y la discriminación de los analitos que se estudian. Según investigaciones (Roussel, 1999) explican que a temperaturas altas se puede mejorar el enriquecimiento de los COV's aumentado su concentración para ser extraídos y analizados, mejorando la sensibilidad de los sensores y los resultados. En algunas ocasiones se presenta un gran inconveniente $y$ es que dependiendo del origen la muestra a temperaturas mayores, esta puede descomponerse provocando resultados poco favorables. En este estudio, de acorde a los resultados obtenidos se evidenció que la mejor discriminación de los analitos mejoró a temperaturas bajas, en este caso la temperatura óptima de clasificación fue $50^{\circ} \mathrm{C}$ (YE Santafé, BD Chaparro, 2013).

Por último, se analizaron muestras de agua estéril, $\mathrm{y}$ tres especies bacterianas, con el objeto de evaluar la especificidad del método propuesto.

Se consideró el caso donde todas las muestras de las tres especies bacterianas y agua esteril se combinaron en un solo conjunto de datos. En la Fig. 12 ¡Error! No se encuentra el origen de la referencia., se observa una buena discriminación de los clusters entre las diferentes categorias usando PCA (97.9\% de varianza). La característica más llamativa es la clara mejora en la separación entre las tres categorías y agua estéril cuando se usa DFA (Fig. 13;Error! No se encuentra el origen de la referencia.) obteniéndose una precisión de clasificación del 100\%. El análisis PCA también revela, que las respuestas del olfato electrónico para las muestras de E. coli, no parecen ser tan diferentes de las muestras de Pseudomonas y Klebsiella, algunos trabajos han identificado cierto grado de especificidad en términos de compuestos orgánicos volátiles característicos para cada tipo de bacteria que son comunes en las especies de interés debido a vías metabólicas compartidas, sin embargo, es difícil determinar la razón de este comportamiento, hacerlo implicaría realizar la caracterización de los COV's resultantes de los productos metabólicos de las cepas de $E$. coli, Pseudomonas y Klebsiella con técnicas analíticas (como GC / MS).

Para mejorar y obtener una buena reproducibilidad de los perfiles de los COV's y para que este tipo de análisis estadístico sea más eficiente en cuanto a la identificación de bacterias, se deben tener en cuenta ciertos parámetros como el medio de cultivo escogido para que las bacterias crezcan (dependiendo el medio cambian los COV's), técnica de muestreo, volumen de la muestra, tiempo y temperatura de incubación.

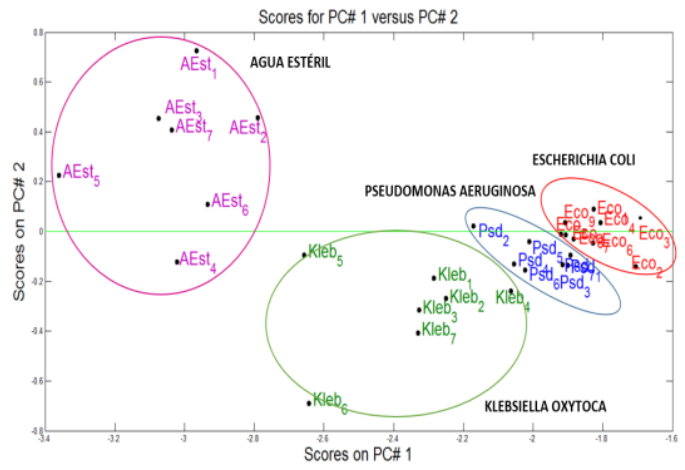

Fig. 12. Resultados con análisis de componentes principales (PCA) de Agua estéril, E. coli, Pseudomonas y Klebsiella a $50^{\circ} \mathrm{C}$.

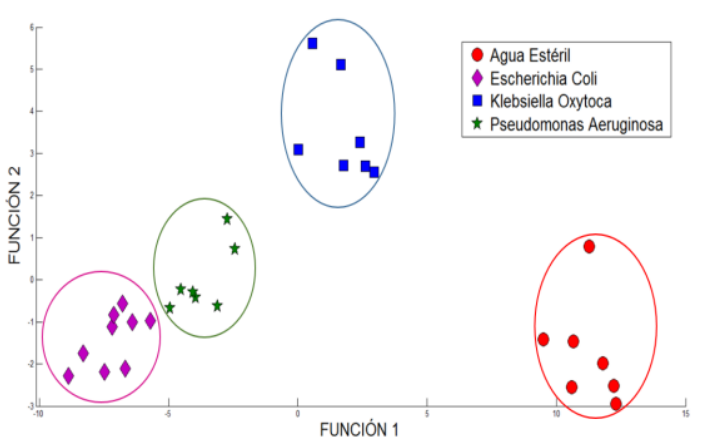

Fig. 13. Resultados con análisis de componentes principales (DFA) de Agua estéril, E. coli,

Pseudomonas y Klebsiella a $50^{\circ} \mathrm{C}$.

En términos generales, el método propuesto demostró una buena repetibilidad y selectividad.

\section{RECONOCIMIENTO}


Se agradece la colaboración de los ingenieros electrónicos Emily Trujillo y Jorge Portilla, los cuales dieron soporte al diseño y desarrollo del equipo de extracción, adicionalmente a las contribuciones del Grupo de Investigación Sistemas Multisensoriales y Reconocimiento de Patrones (GISM) y al grupo de investigación de microbiología y biotecnología (GIMBIO) de la Universidad de Pamplona.

\section{CONCLUSIONES}

En este trabajo se diseñó e implemento un equipo de extracción de volátiles con el objetivo de aumentar la concentración de la muestra y aprovechar la mayor cantidad de COV's que producen las especies bacterianas durante su crecimiento (incubación). Este equipo fue acoplado a un sistema de olfato electrónico que consiste en 16 sensores de gases químicos. Debido a que la composición química de cada sensor en el conjunto es diferente, cada uno responde de una manera única dentro del conjunto, las respuestas generadas se digitalizan y, a partir de ellas, se extraen las características relevantes. Con el desarrollo del método propuesto fue posible determinar de forma rápida, bajo costo y portabilidad la contaminación bacteriana en muestras de agua, para evaluar su calidad para el consumo humano.

De acuerdo a las mediciones realizadas entre las muestras de agua estéril y $E$. oli a diferentes temperaturas se demostró el buen desempeño y la repetibilidad de las medidas del más del $98.7 \%$ de precisión en la clasificación y discriminación de las especies usando PCA y $100 \%$ para DFA. De acuerdo a los resultados obtenidos y estudios de la literatura, se tomó como temperatura optima de incubación $50^{\circ} \mathrm{C}$ durante un tiempo de 15 minutos, sin embargo, para corroborar la elección de la temperatura y obtener una mayor confiabilidad de los datos, se trabajó con una red neuronal probabilística generando un porcentaje de acierto del $100 \%$, adicionalmente para evaluar el desempeño de la red neuronal, en términos de precisión, eficiencia y fiabilidad se utilizó el método interactivo de validación cruzada leave one out con un desempeño del $90 \%$.

El objetivo a corto plazo podría ser que el método propuesto coincida con la sensibilidad y la especificidad de los métodos convencionales usados para la identificación y clasificación de bacterias. Cabe resaltar que en este estudio se alcanzó a evaluar la especificidad del método evaluando la capacidad del olfato electrónico
Revista Colombiana de

Tecnologías de Avanzada

acoplado a al equipo de extracción para diferenciar un analito de interés, en este caso E. coli, que es una bacteria indicadora de contaminación fecal en aguas (control positivo), de otros analitos que son similares y pueden tender a la confusión. Por esta razón para ello se escogieron como controles de especificidad a Pseudomonas aeruginosa, una bacteria Gram (-) de importancia en aguas y Klebsiella oxytoca otra bacteria Gram (-), perteneciente a la misma familia de E. coli. Los resultados obtenidos muestran una buena discriminación usando PCA (97.9\% de varianza) y una precisión en la clasificación del $100 \%$ con DFA. A través de la red PNN se obtuvo un porcentaje de clasificación del $100 \%$ y usando el método de validación cruzada el porcentaje de acierto fue del $86.6 \%$, lo que nos indica que el método propuesto es una herramienta capaz de discriminar entre si los diferentes tipos de bacterias y adicionalmente del agua estéril.

\section{REFERENCIAS}

Organización mundial de la salud. Guías para la calidad del agua potable. Vol. 1: Recomendaciones. Tercera edición. http://www.who.int/water_sanitation_heal th/dwq/gdwq3_es_fulll_lowsres.pdf. (10 de agosto de 2018)

Edberg S., C. Rice E., W. R.J. y Allen M.., J. (2012). Escherichia coli: the best biological drinking water indicator for public health protection. Revista Journal of Applied Microbiology.

Gardner J., W. Craven M. C. Hines E., L. (1998). The prediction of bacteria type and culture growth phase by an electronic nose with a multi-layer perceptron network, Measurement Science and Technology 9 120-127.

Siripatrawan U. (2008) Self-organizing algorithm for classification of packaged fresh vegetable potentially contaminated with foodborne pathogens, Sensors and Actuators B: Chemical 128 (2) 435-441.

McEntegart C., M. Penrose W., R. Strathmann S. Stetter J., R. (2000). Detection and discrimination of coliform bacteria with gas sensor arrays, Sensors and Actuators B: Chemical 70 (1-3) 170-176.

Green G., C., Chan A., D. Dan H. Lin M. (2011). Using a metal oxide sensor (MOS)-based electronic nose for discrimination of bacteria based on individual colonies in suspension, Sensors and Actuators B: Chemical 152 (1) 21-28.

J. Guzmán-Luna, I. D. Torres, J. F. Alvarez. (2014). 
Propuesta de un generador de aplicaciones educativas basadas en televisión digital usando arquitectura de cómputo en la nube. REVISTA COLOMBIANA DE TECNOLOGÍAS DE AVANZADA, ISSN: 1692-7257. 1(23).

J. Guzmán Luna, I. Torres and J. Alvarez. (2014). Propuesta de un generador de aplicaciones educativas basadas en televisión digital usando arquitectura de cómputo en la nube. REVISTA COLOMBIANA DE TECNOLOGÍAS DE

AVANZADA, vol. 1, no. 23, 2014.

Pearce T., C. (2003) Handbook of Machine Olfaction: Electronic Nose Technology, Wiley-VCH.

Krishnamurthy N. Supreetha B., S. Deccaraman M. Vijayashree N. (2012). E-Nose System to Detect E-Coli in Drinking Water of Udupi District. International Journal of Engineering Research and Development 1(12) 58-64

Lakshmanan R., S. Guntupalli R. Hu J. Petrenko V., A. Barbaree J., M y Chin B., A. (2007). Detection of Salmonella typhimurium in fat free milk using a phage immobilized magnetoelastic sensor, Sens. Actuators B: Chem. 126 544-550.

Nuñez c., E. Sberveglieri V y Pulvirenti A. (2013). Detection of Microorganisms in Water and different Food Matrix by Electronic Nose. Seventh International Conference on Sensing Technology.

Green G. Chan A y Lin M. (2014). Robust identification of bacteria based on repeated odor measurements from individual bacteria colonies. Sensors and Actuators B 190 16- 24.

Durán, Cristhian M. (2005). Diseño y optimización de los subsistemas de un sistema de olfato electrónico para aplicaciones agroalimentarias e Industriales. Ed. Universitat Politécnica de Catalunya, Capitulo I, Pag. 3-10. España.

Herrero J., L. Lozano J. Santos J y Suarez J. (2016). On-line classification of pollutants in water using wireless portable electronic noses. Chemosphere 152 107e116.

Sauer S y Kliem M. (2010). Mass spectrometry tools for the classification and identification of bacteria, Nature Reviews Microbiology 8 7482.

Zapata A y Ramírez S. (2015). A Comparative Study of McFarland Turbidity Standards and the Densimat Photometer to Determine Bacterial Cell Density. Curr Microbiol 70 907-909.

Moreno I. Caballero R. Galán R. Matia $\mathrm{F}$ y Jiménez A. (2009). La Nariz Electrónica: Estado del Arte. Revista iberoamericana de
Revista Colombiana de

Tecnologías de Avanzada automatica e informatica industrial 6(3) 76-91.

Rodríguez J., C y Duran C., M. (2008). Sistema de olfato electrónico para la detección de compuestos volátiles. Revista Colombiana de Tecnologías de Avanzada 2(12) 1692-7257.

Duran, C. Gualdron, O. (2014) "Nariz electrónica para determinar el índice de madurez del tomate de árbol (Cyphomandra Betacea Sendt ) Electronic Nose to Determine the Maturity Index of the Tree Tomato," .Revista Ingeniería, Investigación y Tecnología, 15(3).

Rubio J., J et al., (2016). Sistema sensor para el monitoreo ambiental basado en redes Neuronales. Ingeniería Investigación y Tecnología 2 211-222.

YE Santafé, BD Chaparro, (2013), Deteccción de patrones característicos con transformadas wavelet en señales electromiográficas del cuádriceps Revista Colombiana de Tecnologías de Avanzada ISSN: 1692-7257. 